\title{
RESEARCH
}

Open Access

\section{Low high-density lipoprotein cholesterol levels are associated with malignant intraductal papillary mucinous neoplasms: A multicenter study}

Cheng Wang ${ }^{1 \dagger}$, Tingting Lin ${ }^{2 \dagger}$, Xinru Wang ${ }^{2+}$, Zhicheng $\mathrm{Yu}^{2}$, Xiaoling Zhuge ${ }^{3}$, Wenjing Cui ${ }^{2}$, Miaomiao Wang $^{2}$, Zhongqiu Wang', Chuangen Guo ${ }^{4^{*}}$ and Xiao Chen ${ }^{2^{*}}$

\begin{abstract}
Background: Intraductal papillary mucinous neoplasms (IPMNs) can potentially undergo malignant transformation. Studies have shown that high-density lipoprotein cholesterol (HDL-c) was associated with the risk of cancer. In this study, the association between HDL-c and the incidence of malignancy in IPMNs was investigated.

Materials and methods: 226 patients with histologically proven IPMNs who underwent surgery were included in the present study. Patients were assigned to a training group $(n=151)$ and validation group $(n=75)$. Patients' demographic information, clinical data, and histopathological evaluation findings were obtained from medical records. Malignant IPMNs were defined as lesions that showed high grade dysplasia and invasive carcinoma. Logistic regression analyses were used to show the association between HDL-c and malignant IPMNs. Receiver operating characteristic (ROC) curves were generated to analyze predictive performance.

Results: The prevalence of low HDL-c levels was higher in patients with malignant IPMNs than in those with nonmalignant IPMNs $(P<0.01)$ in both the training group and validation group. The prevalence of malignant IPMNs decreased with an increase in HDL-c levels both in patients with all types of IPMNs, as well as in those with branchduct IPMNs (BD-IPMNs).Logistic analysis showed that low HDL-c levels were associated with malignant IPMNs (odds ratio $(\mathrm{OR})=20.56,95 \%$ confidence interval $(\mathrm{Cl}): 2.58-163.64, P<0.01)$ in all types of IPMNs and BD-IPMNs $(\mathrm{OR}=17.6$, $95 \% \mathrm{Cl}: 1.16-268.46, P=0.02)$. The predictive performance of mural nodules plus low HDL-c levels was higher than that of mural nodules alone or mural nodules plus cyst size for the identification of malignant BD-IPMNs.
\end{abstract}

Conclusions: HDL-c levels may serve a potential biomarker for identifying malignant IPMNs and improve the predictive ability of malignancy in BD-IPMNs.

Keywords: lipids, HDL-cholesterol, intraductal papillary mucinous neoplasms, pancreas, malignancy, invasive carcinoma, branch duct

\footnotetext{
* Correspondence: hzhzlguocg@zju.edu.cn; chxwin@163.com

${ }^{4}$ Department of Radiology, the First Affiliated Hospital, College of Medicine,

Zhejiang University, 79 Qingchun road, 310003 Hangzhou, China

${ }^{2}$ Department of Radiology, the Affiliated Hospital of Nanjing University of

Chinese Medicine, 155 Hanzhong road, 210029 Nanjing, China

Full list of author information is available at the end of the article
}

(c) The Author(s). 2021 Open Access This article is licensed under a Creative Commons Attribution 4.0 International License, which permits use, sharing, adaptation, distribution and reproduction in any medium or format, as long as you give appropriate credit to the original author(s) and the source, provide a link to the Creative Commons licence, and indicate if changes were made. The images or other third party material in this article are included in the article's Creative Commons. licence, unless indicated otherwise in a credit line to the material. If material is not included in the article's Creative Commons licence and your intended use is not permitted by statutory regulation or exceeds the permitted use, you will need to obtain permission directly from the copyright holder. To view a copy of this licence, visit http://creativecommons.org/licenses/by/4.0/ The Creative Commons Public Domain Dedication waiver (http://creativecommons.org/publicdomain/zero/1.0/) applies to the data made available in this article, unless otherwise stated in a credit line to the data. 


\section{Introduction}

Intraductal papillary mucinous neoplasms (IPMNs) are common cystic neoplasms of the pancreas. IPMNs can potentially undergo malignant transformation, with the development of invasive carcinoma in some patients [1]. Histopathologically, IPMNs have the potential to progress from low-grade dysplasia to invasive carcinoma over the time $[2,3]$. The incidence of high-grade dysplasia or pancreatic cancer in IPMNs is $42 \%$ [4]. IPMNs are categorized into the following types based on the degree of involvement of the pancreatic ductal system: main duct (MD), branch duct (BD), and mixed type IPMNs (showing features of MD and $\mathrm{BD}$ ). In view of the high risk of malignancy, surgical intervention is recommended for MD-IPMNs and mixed IPMNs with main pancreatic duct (MPD) $>10 \mathrm{~mm}$, jaundice or mural nodules [5].Management of BD-IPMNs remains challenging.

High-risk stigmata and worrisome features include the main pancreatic duct (MPD) diameter and an enhanced mural nodule $>5 \mathrm{~mm}$ that are used as predictors of high-grade dysplasia or invasive carcinoma [6]. Several studies have also shown that the elevated tumor biomarkers including carcinoembryonic antigen (CEA) and serum carbohydrate antigen 19-9 (CA19-9) levels are associated with invasive carcinoma in IPMNs [5]. However, the predictive ability of these biomarkers remains unsatisfactory because of their inadequate sensitivity (lower than 50\%) and specificity [6]. There are inconsistencies among published guidelines [7]. Cut-off value of cyst diameter is set at $4.0 \mathrm{~cm}$ in European guideline [8], but it is set as $3.0 \mathrm{~cm}$ in Fukuoka guideline [6].The follow-up management is also different among guidelines. In addition, a few studies have reported the use of an extracellular vesicle as a novel approach to predict malignant IPMNs [9]. However, few biomarkers have been reported to identify malignancy in BD-IPMNs.

Cholesterol plays a critical role in cancer progression by enhancing cell proliferation, migration, and invasion [10]. High-density lipoprotein (HDL) is the predominant lipoprotein cholesterol that transports cholesterol into major steroidogenic organs $[11,12]$. The anticancer action of HDL is attributed to its pleiotropic properties, including its anti-oxidative action, modulation of cytokine production, inhibition of apoptosis, as well as promotion of cell growth and migration [13, 14]. HDL potentially antagonizes the two primary hallmarks of cancer progression via its potent antioxidant and anti-inflammatory activity $[15,16]$. The association between high density lipoprotein-cholesterol (HDL-c) and cancer risk is also reported, including breast cancer [12, 17], prostate and ovarian cancer [12]. A similar correlation was also observed between HDL-c levels and risk of gastrointestinal cancer, such as liver cancer $[18,19]$, biliary tract cancer $[20,21]$ and pancreatic cancer $[12,22,23]$. However, to our knowledge, no study has investigated the association between HDL-c levels and IPMNs. In this multicenter study the association between HDL-c levels and the incidence of malignancy in IPMNs, particularly in BDIPMNs, was investigated.

\section{Materials and methods Patients}

This multicenter (three-center) study included 226 patients with biopsy-proven IPMNs who underwent surgery during 2011-2020 after excluding those patients with data missing or receiving chemotherapy/radiotherapy. Patients were categorized into the following groups: 151 patients in center 1 and center 2 were set as training group and 75 patients in center 3 was assigned to validation group. Patients' demographic information, clinical data, and pathological features were obtained from medical records. The following data: preoperative symptoms (such as abdominal symptoms and overt jaundice), serum carbohydrate antigen 19-9 (CA19-9) level, serum carcinoembryonic antigen (CEA) levels, HDL-c, low-density lipoprotein (LDL), triglyceride (TG) and total cholesterol (TC) levels, were recorded. Clinical biochemical test was performed by the automatic biochemical analyzer (210 and 7480 Hitachi, Japan). The medical history of pancreatitis and diabetes mellitus (DM) was also collected. A cut-off value of $0.7 \mathrm{mmol} / \mathrm{L}$ was chosen for HDL-c levels based on previous studies [19, 22]. Fasting and 2-hour plasma glucose levels were determined within one week preoperatively. DM was defined according to plasma glucose levels and a history of DM. Imaging information was obtained from the picture archiving and communication system. This retrospective study was approved by the Institutional Ethics Review Board of the First Affiliated Hospital, Zhejiang University School of Medicine. Informed consent was waived.

\section{Imaging analysis}

All patients underwent magnetic resonance imaging (MRI) examinations (Signa HDx 3.0T, GE Medical Systems, USA; or Achieva 3.0T, Philips, The Netherland). T1 weighted imaging (T1WI), T2WI, magnetic resonance cholangiopancreatography and contrast-enhanced imaging were obtained. The following imaging findings were recorded: MPD diameter, enhanced mural nodules, cyst location, cyst size and the communication with the MPD, if any.

\section{Malignant intraductal papillary mucinous neoplasms}

IPMN was classified into three types based on the extent of involvement of the pancreatic ductal system: the MD, $\mathrm{BD}$, and mixed types. Histopathologically, IPMNs was categorized as low-intermediate dysplasia, high-grade dysplasia, or invasive adenocarcinoma. Malignant IPMNs 
were defined as those which showed features of highgrade dysplasia and associated invasive carcinoma.

\section{Statistical analysis}

Based on HDL-c levels, patients were categorized into the following groups: those with HDL-c levels $<0.7$ $\mathrm{mmol} / \mathrm{L}$ and those with HDL-c levels $\geq 0.7 \mathrm{mmol} / \mathrm{L}$. The two-tailed t tests or Mann-Whitney U-test was used to compare the variables. Univariate and multivariate logistic regression analyses were used to determine the association between low HDL-c levels and malignant IPMNs. The results were adjusted for diabetes and pancreatitis. Receiver operating characteristic (ROC) curves were generated to analyze the performance of mural nodules plus low HDL-c levels as predictor of malignant IPMNs. A p value less than 0.05 was considered statistically significant.

\section{Results}

\section{Patients' clinical data}

The clinical data of patients in training group and validation group is shown in Table 1. Malignant IPMNs were diagnosed in 47 patients $(31.1 \%)$ in the training group and in 19 patients $(25.3 \%)$ in the validation group. The prevalence of low HDL-c levels was higher in patients with malignant IPMNs than in patients with nonmalignant IPMNs $(P<0.01)$ in both training and validation groups. Of the patients with low HDL-c levels, $77.8 \%$ had malignant IPMNs. Similar result was observed in validation group $(75.0 \%)$. The prevalence of malignant IPMNs tended to decrease with an increase in HDL-c levels in patients with all type IPMNs and BDIPMNs (Fig. 1).

\section{The association between low HDL-c and malignant IPMNs} Univariate and multivariate logistic regression analyses were used to identify the associated factors for malignant IPMNs (Table 2). Compared with MD involved IPMNs, BD-IPMNs had a lower risk for malignancy $(\mathrm{OR}=0.13$, $95 \%$ CI: 0.05-0.34). However, this association was no longer present after adjustment for high risk stigmata (diameter of MPD and mural nodules). Low HDL-c levels were associated with the presence of malignant IPMNs (OR = 8.93, 95 \% CI: 1.78-44.80), and such association remained after adjustment for DM, pancreatitis and serum LDL levels (OR $=20.56$, $95 \%$ CI: $2.58-$ 163.64). A similar trend was observed in the validation group $(\mathrm{OR}=6.66,95 \% \mathrm{CI}: 1.08-41.06)$.

Subsequently, the association between low HDL-c levels and malignancy in BD-IPMNs was observed (Table 3). Subgroup analysis also showed that low HDL-c levels were associated with the presence of malignant IPMNs $(\mathrm{OR}=17.6,95 \% \mathrm{CI}: 1.16-268.46)$ in BD-IPMNs.

\section{ROC analysis}

The ROC curve showed that the area under the curve (AUC) of mural nodules plus the MPD diameter and low HDL-c levels (AUC $=0.82$, $95 \%$ CI: 0.74-0.89, $P<$ 0.01 ) was slightly higher than that of mural nodule plus MPD diameter and Ca19-9 levels $(\mathrm{AUC}=0.81,95 \% \mathrm{CI}$ : $0.73-0.89, P<0.01)$ in identifying malignant IPMNs (Fig. 2). Moreover, the area under the curve (AUC) of mural nodules plus low HDL-c $(\mathrm{AUC}=0.81,95 \% \mathrm{CI}$ : $0.62-0.99, P<0.01)$ was higher than that of mural nodules alone (AUC $=0.71,95 \% \mathrm{CI}: 0.49-0.92, P=0.046$ ) or mural nodules plus the cyst size $(\mathrm{AUC}=0.76,95 \% \mathrm{CI}$ : $0.57-0.95, P=0.02$ ) for prediction of malignant BDIPMNs (Fig. 2).

\section{Discussion}

The diagnosis and clinical management strategies of patients with IPMNs remain controversial currently owing to the lack of accurate predictors of malignant transformation in these lesions [24, 25]. Tumor biomarkers, such as CEA and CA19-9levels have been used to predict the malignancy [5]. This study showed an inverse association between HDL-c levels and IPMNs. The prevalence of low HDL-c levels was significantly higher in the malignant IPMN than in the non-malignant IPMN group. Multivariable logistic analysis further showed that low HDL-c levels were associated with occurrence of malignant IPMNs. In addition, the combination of mural nodules and low HDL-c levels showed higher performance than that of mural nodules alone or of a combination of mural nodule and cyst size in predicting malignant BD-IPMNs. Low HDL-c levels may be potential biomarkers for malignant IPMNs.

Studies have reported an inverse relationship between serum TC levels and cancer risk [26-28]. Studies have also reported an association between HDL-c levels and cancer risk, as well as disease free survival and overall survival in many type of malignancies [12, 17-23, 29]. Low HDL-c levels were associated with a high TNM stage and occurrence of distant metastasis [30]. Notably, several studies have reported an inverse association between HDL-c levels and gastrointestinal cancer. Randomized controlled intervention studies have reported [22] that the inverse associations between HDL-c levels and pancreatic cancer was not materially affected by other lipids, and the inverse association remained unchanged after exclusion of the first 3 years of follow-up. Michalaki et al. [23] reported that serum HDL concentration was significantly lower in patients with pancreatic cancer than in the controls. Compared with the control group, patients with pancreatic cancer showed at least 2fold lower serum apolipoprotein A-II, transthyretin, and apolipoprotein A-I levels [31]. HDL-c levels were inversely associated with the risk of liver cancer [18], and 
Table 1 Clinical data in malignant and non-malignant IPMNs

\begin{tabular}{|c|c|c|c|c|c|c|c|c|}
\hline & \multicolumn{4}{|c|}{ Training group (center 1 and Center 2) } & \multicolumn{4}{|c|}{ Validation group (center 3 ) } \\
\hline & $\begin{array}{l}\text { Total }(n= \\
151)\end{array}$ & $\begin{array}{l}\text { Malignant } \\
\text { IPMN } \\
(n=47)\end{array}$ & $\begin{array}{l}\text { Non- } \\
\text { malignant } \\
\text { IPMN } \\
(n=104)\end{array}$ & $P$ & Total $(n=75)$ & $\begin{array}{l}\text { Malignant } \\
\text { IPMN } \\
(n=19)\end{array}$ & $\begin{array}{l}\text { Non- } \\
\text { malignant } \\
\text { IPMN } \\
(n=56)\end{array}$ & $P$ \\
\hline Age & $63.28 \pm 9.47$ & $63.59 \pm 8.99$ & $62.60 \pm 10.50$ & 0.55 & $64.8 \pm 8.90$ & $68.42 \pm 8.25$ & $63.68 \pm 8.86$ & 0.44 \\
\hline Size & $3.69 \pm 1.98$ & $3.93 \pm 1.63$ & $3.58 \pm 2.11$ & 0.34 & $3.1 \pm 1.12$ & $3.8 \pm 1.33$ & $2.5 \pm 0.93$ & 0.02 \\
\hline Sex(male/female) & $95 / 56$ & $34 / 13$ & $61 / 43$ & 0.11 & $49 / 26$ & $11 / 8$ & $38 / 18$ & 0.43 \\
\hline Dysplasia & & & & / & & & & / \\
\hline Low-intermediate grade & 104 & / & 104 & & 56 & 0 & 56 & \\
\hline High-grade & 24 & 24 & 0 & & 11 & 11 & 0 & \\
\hline Invasion & 23 & 23 & 0 & & 8 & 8 & 0 & \\
\hline Type & & & & $<0.01$ & & & & $<0.01$ \\
\hline Main & 24 & 16 & 8 & & 14 & 8 & 6 & \\
\hline Branch & 73 & 9 & 64 & & 46 & 6 & 40 & \\
\hline Mixed & 54 & 22 & 32 & & 15 & 5 & 10 & \\
\hline Location & & & & 0.11 & & & & 0.94 \\
\hline Head-neck & 95 & 34 & 61 & & 41 & 9 & 32 & \\
\hline Body and Tail & 56 & 13 & 43 & & 34 & 10 & 24 & \\
\hline CEA (ng/ml) & $3.57 \pm 3.61$ & $4.75 \pm 5.65$ & $3.03 \pm 1.95$ & 0.09 & $3.99 \pm 10.03$ & $8.51 \pm 19.29$ & $2.43 \pm 1.59$ & 0.03 \\
\hline CA19-9 (U/ml) & $48.68 \pm 228.65$ & $99.04 \pm 396.08$ & $26.19 \pm 70.67$ & 0.002 & $71.37 \pm 204.27$ & $132.83 \pm 270.4$ & $50.15 \pm 174.53$ & 0.13 \\
\hline HDL-c (mmol/L) & $1.19 \pm 0.39$ & $1.10 \pm 0.52$ & $1.21 \pm 0.31$ & 0.38 & $1.02 \pm 0.39$ & $0.84 \pm 0.41$ & $1.08 \pm 0.37$ & 0.02 \\
\hline HDL-c $<0.7$ & 9 & 7 & 2 & $<0.01$ & 12 & 9 & 3 & $<0.01$ \\
\hline LDL (mmol/L) & $2.51 \pm 0.82$ & $2.52 \pm 0.69$ & $2.51 \pm 0.89$ & 0.95 & $2.27 \pm 0.69$ & $1.91 \pm 0.65$ & $2.40 \pm 0.67$ & 0.01 \\
\hline MPD diameter & $0.61 \pm 0.41$ & $0.90 \pm 0.49$ & $0.48 \pm 0.29$ & $<0.001$ & & $0.97 \pm 0.42$ & $0.43 \pm 0.21$ & $<0.01$ \\
\hline Pancreatitis & 3 & 0 & 3 & 0.24 & 1 & 0 & 1 & 0.25 \\
\hline Diabetes & 23 & 9 & 14 & 0.13 & 4 & 1 & 3 & 1.0 \\
\hline $\begin{array}{l}\text { Lymph node metastasis (yes vs. } \\
\text { no) }\end{array}$ & 2 & 2 & 0 & 0.09 & & 0 & 0 & / \\
\hline Peripancreatic extension & 5 & 5 & 0 & 0.003 & 1 & 1 & 0 & 0.45 \\
\hline Mural nodule & 17 & 13 & 4 & $<0.01$ & 8 & 5 & 3 & 0.01 \\
\hline
\end{tabular}

Malignant intraductal papillary mucinous neoplasms (IPMNs) were defined as those with high grade dysplasia and associated invasive carcinoma

CA 19 - 9: carbohydrate antigen 19-9; CEA: carcinoembryonic antigen; MPD: main pancreatic duct; HDL-c: high-density lipoprotein-cholesterol; LDL: low density lipoprotein

preoperative HDL-c levels were associated with the risk of cancer recurrence [19]. Compared with the reference group, patients in the lowest quintile of HDL-c $(<30 \mathrm{mg} / \mathrm{dL})$ had an 11.6-fold higher risk of gallbladder cancer and a 16.8-fold higher risk of bile duct cancer [21]. Moreover, raising HDL levels may be a potential therapeutic strategy for against cancer [32]. However, the association between HDL-c levels and malignant IPMNs has not been clarified.

Interestingly, this study showed that a low serum HDL-c level was an independent risk factor for malignancy in IPMNs both in the training and validation groups even after adjustment for confounders. In addition, the diagnostic performance of mural nodules plus the MPD diameter and low HDL-c was similar to that of mural nodules plus the MPD diameter and CA19-9 levels. Management of BD-IPMNs remains challenging [33]. Few biomarkers are available for the diagnosis of malignant transformation in BD-IPMNs. Our data showed that low serum HDL-c levels improved the diagnostic performance of mural nodules in predicting malignant BD-IPMNs. The AUC increased from 0.71 to 0.81 . Interestingly, we also observed an inverse association between low HDL-c levels $(<0.8 \mathrm{mmol} / \mathrm{L})$ and grade 3 pancreatic neuroendocrine neoplasms (PNENs) ( $n=197$, data not shown). These data further support the finding that low HDL-c levels are associated with pancreatic malignancy. However, conflicting evidence was also reported between HDL levels and cancer incidence or mortality because this association may depend 

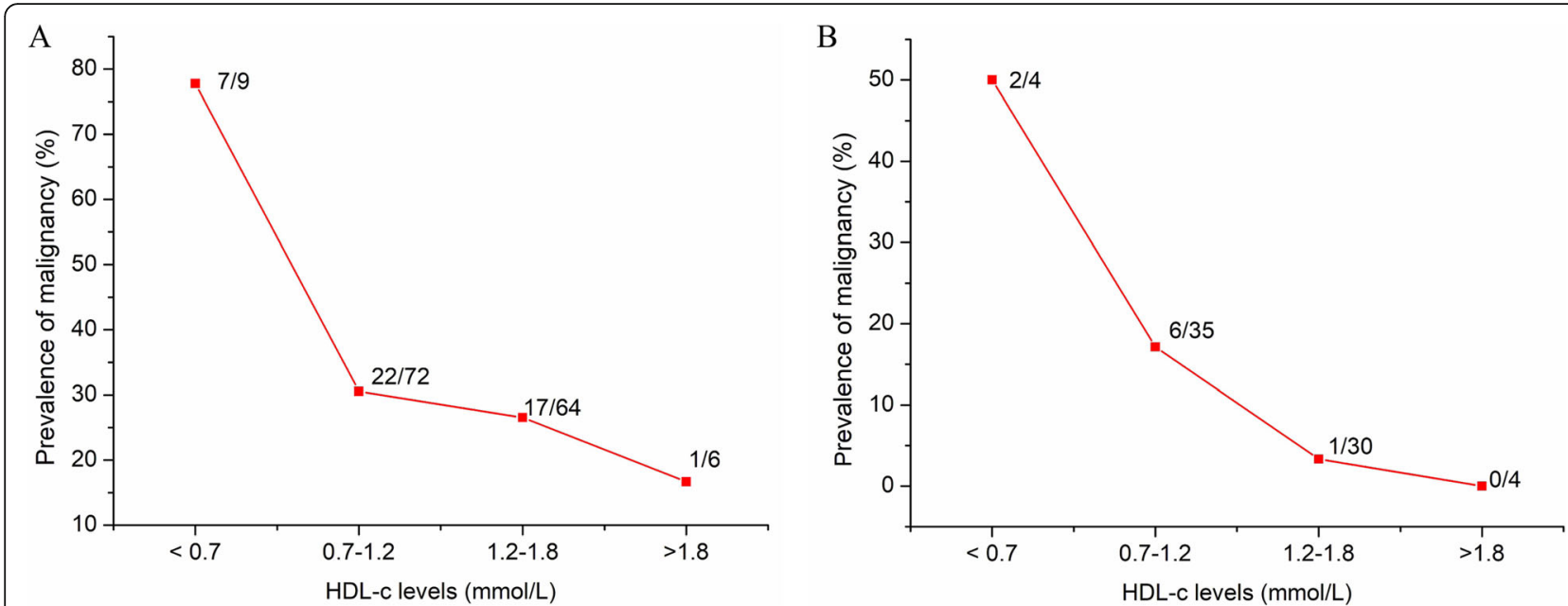

Fig. 1 The association between the prevalence of malignant intraductal papillary mucinous neoplasms (IPMNs) and high-density lipoprotein cholesterol (HDL-c) levels. The prevalence of malignancy decreased with an increase of HDL-c in all IPMNs (A) and branch duct intraductal papillary mucinous neoplasm (BD-IPMNs) (B)

upon tumor type [32]. However, an increasing body of evidence supports the association [12, 32]. The association between HDL and IPMNs occurrence were not analyzed in this study and requires further investigations.

The possible mechanism between HDL and cancer development or progression has not been totally clarified. HDL-associated proteins may have antioxidant, antiinflammatory, antiangiogenic, and immunomodulatory properties which may contribute to antitumorigenic effects [29]. In addition, cancer cells express high levels of the scavenger receptor type B-I lipoprotein receptor, which promotes lipid internalization and lipoprotein consumption by cancer cells [33]. Low levels of circulating HDL-c may be attributable to the fact that cancer cells utilize a large amount of cholesterol for the formation of new membranes [33]. Moreover, HDL-c levels do not always correlate with HDL function and cholesterol is only one component of HDL [34]. Further studies are

Table 2 Associated factors with malignant IPMNs

\begin{tabular}{|c|c|c|c|c|c|c|c|c|c|c|}
\hline \multirow{3}{*}{ variables } & \multicolumn{6}{|c|}{ Training group (center 1 and center 2) } & \multicolumn{4}{|c|}{ Validation group (center 3 ) } \\
\hline & Univariable & & Multivariable & & & & Multivariable & & & \\
\hline & OR $(95 \% \mathrm{Cl})$ & $P$ & Model 1 & $P$ & Model 2 & P & Model 1 & P & Model 2 & $P$ \\
\hline & & & OR $(95 \% \mathrm{Cl})$ & & OR $(95 \% \mathrm{Cl})$ & & OR $(95 \% C l)$ & & OR $(95 \% \mathrm{Cl})$ & \\
\hline Mural nodule (yes vs. no ) & $\begin{array}{l}9.56 \\
(2.92-31.30)\end{array}$ & $<0.01$ & $\begin{array}{l}15.14 \\
(3.10-74.07)\end{array}$ & $<0.01$ & $\begin{array}{l}14.51 \\
(3.05-69.02)\end{array}$ & $<0.01$ & $\begin{array}{l}16.11 \\
(2.78-93.5)\end{array}$ & $<0.01$ & $\begin{array}{l}25.2 \\
(3.43-185.4)\end{array}$ & $<0.01$ \\
\hline Duct $(\mathrm{cm})$ & $\begin{array}{l}18.0 \\
(5.84-55.52)\end{array}$ & $<0.01$ & $\begin{array}{l}10.45 \\
(1.78-61.17)\end{array}$ & 0.02 & $\begin{array}{l}11.61 \\
(1.88-71.65)\end{array}$ & 0.02 & $\begin{array}{l}15.4 \\
(2.36-89.6)\end{array}$ & $<0.01$ & $\begin{array}{l}18.76 \\
(3.32-165.3)\end{array}$ & $<0.01$ \\
\hline Size $(\mathrm{cm})$ & $\begin{array}{l}1.09 \\
(0.91-1.30)\end{array}$ & 0.42 & $\begin{array}{l}0.99 \\
(0.79-1.23)\end{array}$ & 0.97 & $\begin{array}{l}0.95 \\
(0.76-1.19)\end{array}$ & 0.71 & $\begin{array}{l}1.07 \\
(0.86-1.28)\end{array}$ & 0.68 & $\begin{array}{l}1.06 \\
(0.86-1.31)\end{array}$ & 0.70 \\
\hline Type & & $<0.01$ & & 0.11 & & 0.10 & & $<0.01$ & & $<0.01$ \\
\hline $\mathrm{MD}+\mathrm{MT}$ & 1 & & 1 & & 1 & & 1 & & 1 & \\
\hline Branch-duct & $\begin{array}{l}0.15 \\
(0.07-0.34)\end{array}$ & & $\begin{array}{l}0.39 \\
(0.10-1.53)\end{array}$ & & $\begin{array}{l}0.38 \\
(0.09-1.53)\end{array}$ & & $\begin{array}{l}0.21 \\
(0.10-0.37)\end{array}$ & & $\begin{array}{l}0.16 \\
(0.09-0.28)\end{array}$ & \\
\hline Location & & 0.11 & & 0.28 & & 0.38 & & 0.49 & & 0.53 \\
\hline Head-neck & 1 & & 1 & & 1 & & 1 & & 1 & \\
\hline Body-Tail & $\begin{array}{l}0.54 \\
(0.26-1.15)\end{array}$ & & $\begin{array}{l}0.57 \\
(0.22-1.50)\end{array}$ & & $\begin{array}{l}0.62 \\
(0.23-1.63)\end{array}$ & & $\begin{array}{l}0.47 \\
(0.18-1.21)\end{array}$ & & $\begin{array}{l}0.50 \\
(0.20-1.27)\end{array}$ & \\
\hline $\mathrm{HDL}-\mathrm{c}(<0.7 \mathrm{vs} . \geq 0.7 \mathrm{mmol} / \mathrm{L})$ & $\begin{array}{l}8.93 \\
(1.78-44.80)\end{array}$ & $<0.01$ & $\begin{array}{l}17.92 \\
(2.40-134.17)\end{array}$ & $<0.01$ & $\begin{array}{l}20.56 \\
(2.58-163.64)\end{array}$ & $<0.01$ & $\begin{array}{l}6.63 \\
(1.14-38.47)\end{array}$ & 0.02 & $\begin{array}{l}6.66 \\
(1.08-41.06)\end{array}$ & 0.02 \\
\hline
\end{tabular}

Model 1 was adjusted with body mass index, age and gender; Model 2 was additionally adjusted with pancreatitis, low density lipoprotein levels and diabetes HDL-c: high-density lipoprotein cholesterol; MD: main duct; MT: mixed type 
Table 3 Associated factors with malignant IPMNs in BD-IPMN

\begin{tabular}{|c|c|c|c|c|c|c|}
\hline \multirow[t]{2}{*}{ variables } & \multicolumn{2}{|l|}{ Univariable } & \multicolumn{4}{|l|}{ Multivariable } \\
\hline & OR (95 \%Cl) & $P$ & Model 1 & $P$ & Model 2 & $P$ \\
\hline & & & OR $(95 \% \mathrm{Cl})$ & & OR (95 \%Cl) & \\
\hline Mural nodule (yes vs. no) & $24.80(3.61-170.3)$ & $<0.01$ & $50.6(5.12-499.6)$ & $<0.01$ & $52.8(5.29-528.2)$ & $<0.01$ \\
\hline Duct $(\mathrm{cm})$ & $1.24(0.01-170.5)$ & 0.93 & $19.45(0.04-1000.0)$ & 0.35 & $17.6(0.04-820.7)$ & 0.35 \\
\hline Size $(\mathrm{cm})$ & $1.12(0.86-1.46)$ & 0.40 & $1.08(0.77-1.52)$ & 0.65 & $1.11(0.78-1.56)$ & 0.95 \\
\hline $\mathrm{HDL}-\mathrm{c}(<0.7 \mathrm{vs} . \geq 0.7 \mathrm{mmol} / \mathrm{L})$ & $8.86(1.07-73.1)$ & 0.04 & $15.27(1.19-196.26)$ & 0.04 & $17.6(1.16-268.46)$ & 0.02 \\
\hline
\end{tabular}

Model 1 was adjusted with BMI, age and gender; Model 2 was additionally adjusted with pancreatitis, low density lipoprotein levels and diabetes $\mathrm{Cl}$ : confidence interval; HDL-c: high-density lipoprotein cholesterol; OR: odds ratio

required to explore the mechanism involved in the HDL-mediated anti-tumorigenic effects [12]. Longitudinal studies may supply more strong evidence than a cross-sectional study. Clinical trials may be performed to show the role of statins against the malignant transformation of IPMNs.

\section{Comparisons with other studies and what does the current work add to the existing knowledge}

The associations between HDL-c levels and cancer risk have been reported. Associated factors with malignant IPMNs are also been reported. However, few data showed the associations between HDL-c levels and malignant transformation of IPMNs. The current study reported that low HDL-c levels $(<0.7 \mathrm{mmol} / \mathrm{L})$ was associated with malignancy in IPMNs.

\section{Study strengths and limitations}

This study has several limitations. First, the sample size was relatively small, particularly, the small number of malignant IPMNs or carcinoma in BD-IPMNs. Second, it would be better to perform a longitudinal study to show the association between baseline serum HDL-c levels and develop malignant IPMNs. Third, whether low HDL-c level represent a consequential or causal factor in the development of malignant IPMNs need further exploration. Fourth, some confounders were not considered, such as lifestyle and diet habits. Finally, HDL-associated proteins and enzymes were not easily affected by covariates. We did not observe the association between malignant IPMNs and them. Our study is an exploration.

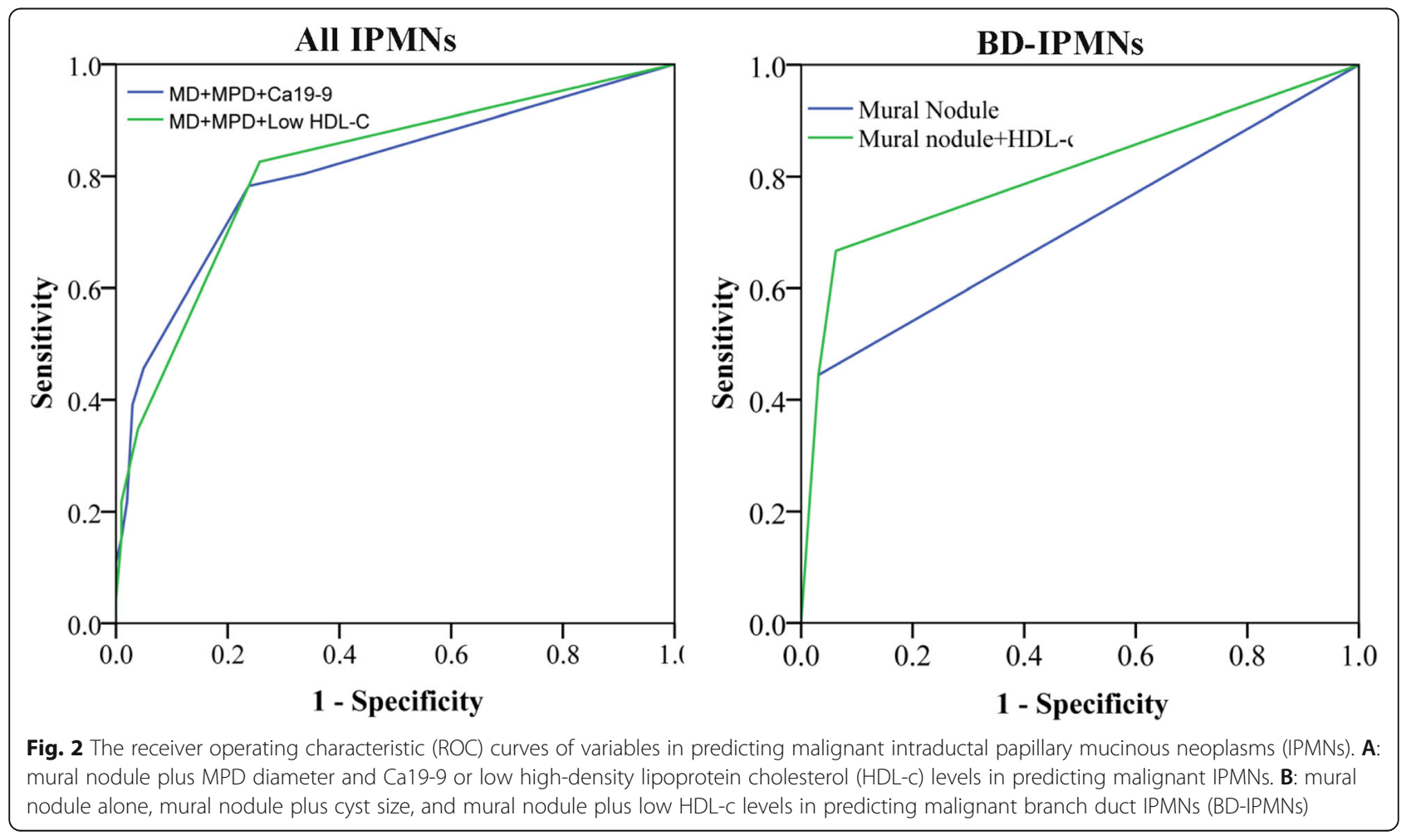




\section{Conclusions}

This study shows that low HDL-c levels are associated with malignant IPMNs and low HDL-c levels may serve as a potential biomarker for identifying malignant IPMNs. Moreover, measurement of HDL-c levels may improve the predictive ability of malignancy in BDIPMNs. Prospective studies are warranted to investigate the association between HDL-c levels and malignant transformation of IPMNs. HDL-c-raising may be a therapeutic strategy against malignant transformation in IPMNs.

\section{Abbreviations \\ AUC: area under the curve; BD: branch duct; CA19-9: carbohydrate antigen 19 - 9; CEA: carcinoembryonic antigen; Cl: confidence interval; HDL-c: high- density lipoprotein-cholesterol; IPMN: intraductal papillary mucinous neoplasms; LDL: low density lipoprotein; MD: main duct; MPD: main pancreatic duct; MT: mixed-type; OR: odds ratio; ROC: receiver operating characteristic}

\section{Acknowledgements}

Not applicable.

\section{Authors' contributions}

Cheng Wang: Data curation, Formal analysis, Writing - original draft, Writing - review \& editing; T. Lin: Data curation, Formal analysis, Writing - review \& editing; X. Wang: Data curation, Formal analysis, Writing - review \& editing; Z. Yu: Data curation, Formal analysis, Writing -draft; X. Zhuge: Data curation, Formal analysis, Writing - original draft, Writing - review \& editing. W.Cui: Formal analysis, Writing - original draft, Writing - review \& editing. M. Wang: Data curation, Formal analysis, Writing - review \& editing; Z.Wang: Formal analysis, Writing- review \& editing. X. Chen: Conceptualization, Methodology, Data curation, Visualization, Writing - review \& editing. C. Guo: Conceptualization, Methodology, Writing - review \& editing. The author(s) read and approved the final manuscript.

\section{Funding}

This study was funded by Zhejiang Provincial Natural Science Foundation (LY18H180004) and Zhejiang Medical Science and Technology Project (2017KY331)

\section{Availability of data and materials}

All data generated or analyzed during this study are included in this published article (and its Supplementary Information files).

\section{Declarations}

Ethics approval and consent to participate

This retrospective study was approved by the Institutional Ethic Review Board of the First Affiliated Hospital, Zhejiang University School of Medicine. Informed consent was waived.

\section{Consent for publication}

Not applicable.

\section{Competing interest}

None.

\section{Author details}

'Department of Radiology, Nanjing Drum Tower Hospital, The Affiliated Hospital of Nanjing University Medical School, 321 Zhongshan road, 210008 Nanjing, China. ${ }^{2}$ Department of Radiology, the Affiliated Hospital of Nanjing University of Chinese Medicine, 155 Hanzhong road, 210029 Nanjing, China. ${ }^{3}$ Department of Laboratory Medicine, the First Affiliated Hospital, College of Medicine, Zhejiang University, 79 Qingchun road, 310003 Hangzhou, China. ${ }^{4}$ Department of Radiology, the First Affiliated Hospital, College of Medicine, Zhejiang University, 79 Qingchun road, 310003 Hangzhou, China.
Received: 22 July 2021 Accepted: 16 August 2021

Published online: 28 August 2021

\section{References}

1. Fernández-del Castillo C, Adsay NV. Intraductal papillary mucinous neoplasms of the pancreas. Gastroenterology. 2010;139(3):708-13.

2. Hruban RH, Takaori K, Klimstra DS, Adsay NV, Albores-Saavedra J, Biankin AV, et al. An illustrated consensus on the classification of pancreatic intraepithelial neoplasia and intraductal papillary mucinous neoplasms. Am J Surg Pathol. 2004;28(8):977-87.

3. Sohn TA, Yeo CJ, Cameron JL, Hruban RH, Fukushima N, Campbell KA, et al. Intraductal papillary mucinous neoplasms of the pancreas: an updated experience. Ann Surg. 2004;239(6):788-97.

4. Scheiman JM, Hwang JH, Moayyedi P. American gastroenterological association technical review on the diagnosis and management of asymptomatic neoplastic pancreatic cysts. Gastroenterology. 2015;148(4): 824-48.

5. Fritz S, Hackert T, Hinz U, Hartwig W, Büchler MW, Werner J. Role of serum carbohydrate antigen $19-9$ and carcinoembryonic antigen in distinguishing between benign and invasive intraductal papillary mucinous neoplasm of the pancreas. Br J Surg. 2011;98(1):104-10.

6. Tanaka M, Fernández-Del Castillo C, Kamisawa T, Jang JY, Levy P, Ohtsuka T, et al. Revisions of international consensus Fukuoka guidelines for the management of IPMN of the pancreas. Pancreatology. 2017;17(5):738-53.

7. Tjaden C, Sandini M, Mihaljevic AL, Kaiser J, Khristenko E, Mayer P, et al. Risk of the Watch-and-Wait Concept in Surgical Treatment of Intraductal Papillary Mucinous Neoplasm. JAMA Surg. 2021; e210950.

8. European Study Group on Cystic Tumours of the Pancreas. European evidencebased guidelines on pancreatic cystic neoplasm. Gut. 2018;67:789804.

9. Yang KS, Ciprani D, O'Shea A, Liss AS, Yang R, Fletcher-Mercaldo S, et al. Extracellular Vesicle Analysis Allows for Identification of Invasive IPMN. Gastroenterology. 2021;160(4):1345-58.

10. Huang B, Song BL, Xu C. Cholesterol metabolism in cancer: mechanisms and therapeutic opportunities. Nature metabolism. 2020;2(2):132-41.

11. Rigotti A, Miettinen HE, Krieger $M$. The role of the high-density lipoprotein receptor SR-BI in the lipid metabolism of endocrine and other tissues. Endocr Rev. 2003;24(3):357-87.

12. Revilla G, Cedó L, Tondo M, Moral A, Pérez لـ Corcoy R, et al. LDL, HDL and endocrine-related cancer: From pathogenic mechanisms to therapies. Semin Cancer Biol. 2021:73:134-57.

13. Ramadori P, Kroy D, Streetz KL. Immunoregulation by lipids during the development of non-alcoholic steatohepatitis. Hepatobiliary surgery nutrition. 2015:4(1):11-23.

14. Inoue M, Kurahashi N, Iwasaki M, Tanaka Y, Mizokami M, Noda M, et al. Metabolic factors and subsequent risk of hepatocellular carcinoma by hepatitis virus infection status: a large-scale population-based cohort study of Japanese men and women (JPHC Study Cohort II). Cancer Causes Control. 2009;20(5):741-50.

15. Georgila K, Vyrla D, Drakos E. Apolipoprotein A-I (ApoA-I), Immunity, Inflammation and Cancer. Cancers (Basel). 2019;11(8):1097.

16. Bacchetti T, Ferretti G, Sahebkar A. The role of paraoxonase in cancer. Semin Cancer Biol. 2019;56:72-86

17. Johnson KE, Siewert KM, Klarin D, Damrauer SM, Chang KM, Tsao PS, et al. The relationship between circulating lipids and breast cancer risk: A Mendelian randomization study. PLoS Med. 2020;17(9):e1003302.

18. Nderitu P, Bosco C, Garmo H, Holmberg L, Malmström H, Hammar N, et al. The association between individual metabolic syndrome components, primary liver cancer and cirrhosis: A study in the Swedish AMORIS cohort. Int J Cancer. 2017;141(6):1148-60.

19. Tian L, Yu Q, Gao XH, Wu J, Ma XL, Dai Q, et al. A new use for an old index: preoperative high-density lipoprotein predicts recurrence in patients with hepatocellular carcinoma after curative resections. Lipids Health Dis. 2017; 16(1):123

20. Hsing AW, Gao YT, Han TQ, Rashid A, Sakoda LC, Wang BS, et al. Gallstones and the risk of biliary tract cancer: a population-based study in China. $\mathrm{Br}$ J Cancer. 2007;97(11):1577-82.

21. Andreotti G, Chen J, Gao YT, Rashid A, Chang SC, Shen MC, et al. Serum lipid levels and the risk of biliary tract cancers and biliary stones: A population-based study in China. Int J Cancer. 2008;122(10):2322-9. 
22. Kabat GC, Kim MY, Chlebowski RT, Vitolins MZ, Wassertheil-Smoller S, Rohan TE. Serum lipids and risk of obesity-related cancers in postmenopausal women. Cancer Causes Control. 2018;29(1):13-24.

23. Michalaki V, Koutroulis G, Syrigos K, Piperi C, Kalofoutis A. Evaluation of serum lipids and high-density lipoprotein subfractions (HDL2, HDL3) in postmenopausal patients with breast cancer. Mol Cell Biochem. 2005;268: 19-24.

24. Zhao W, Guan J, Horswell R, Li W, Wang Y, Wu X, et al. HDL cholesterol and cancer risk among patients with type 2 diabetes. Diabetes Care. 2014; 37(12):3196-203.

25. Heckler M, Brieger L, Heger U, Pausch T, Tjaden C, Kaiser J, et al. Predictive performance of factors associated with malignancy in intraductal papillary mucinous neoplasia of the pancreas. BJS open. 2018;2(1):13-24.

26. Pirro M, Ricciuti B, Rader DJ, Catapano AL, Sahebkar A, Banach M. High density lipoprotein cholesterol and cancer: Marker or causative? Prog Lipid Res. 2018;71:54-69.

27. Ahn J, Lim U, Weinstein SJ, Schatzkin A, Hayes RB, Virtamo J, et al. Prediagnostic total and high-density lipoprotein cholesterol and risk of cancer. Cancer Epidemiol Biomarkers Prev. 2009;18(11):2814-21.

28. Chandler PD, Song Y, Lin J, Zhang S, Sesso HD, Mora S, et al. Lipid biomarkers and long-term risk of cancer in the Women's Health Study. Am J Clin Nutr. 2016;103(6):1397-407.

29. Ridtitid W, DeWitt JM, Schmidt CM, Roch A, Stuart JS, Sherman S, et al. Management of branch-duct intraductal papillary mucinous neoplasms: a large single-center study to assess predictors of malignancy and long-term outcomes. Gastrointest Endosc. 2016;84(3):436-45.

30. Ganjali S, Banach M, Pirro M, Fras Z, Sahebkar A. HDL and cancer - causality still needs to be confirmed? Update 2020. Semin Cancer Biol. 2021;73:169-77.

31. Ehmann M, Felix K, Hartmann D, Schnölzer M, Nees M, Vorderwülbecke S, et al. Identification of potential markers for the detection of pancreatic cancer through comparative serum protein expression profiling. Pancreas. 2007;34(2):205-14.

32. Ganjali S, Ricciuti B, Pirro M, Butler AE, Atkin SL, Banach M, et al. HighDensity Lipoprotein Components and Functionality in Cancer: State-of-theArt. Trends Endocrinol Metab. 2019;30(1):12-24.

33. Morin EE, Li X-A, Schwendeman A. HDL in Endocrine Carcinomas: Biomarker, Drug Carrier, and Potential Therapeutic. Front Endocrinol (Lausanne). 2018;9:715.

34. Escolà-Gil JC, Cedó L, Blanco-Vaca F. High-density lipoprotein cholesterol targeting for novel drug discovery: where have we gone wrong? Expert Opin Drug Discov. 2014;9(2):119-24.

\section{Publisher's Note}

Springer Nature remains neutral with regard to jurisdictional claims in published maps and institutional affiliations.

Ready to submit your research? Choose BMC and benefit from:

- fast, convenient online submission

- thorough peer review by experienced researchers in your field

- rapid publication on acceptance

- support for research data, including large and complex data types

- gold Open Access which fosters wider collaboration and increased citations

- maximum visibility for your research: over $100 \mathrm{M}$ website views per year

At $\mathrm{BMC}$, research is always in progress.

Learn more biomedcentral.com/submissions 